lar walls of this organ. Dr. Leared says it is absolutely impossible. An universal negative is a very sweeping assertion-absolutely impossible to any and every human being. This is what Dr. Leared says, but I venture to think he means " absolutely impossible to $m e$ "; and I hope I shall have his thanks for the alteration I suggest. My own assertion then becomes, "It is easy to me", and I have only to show how the element of friction is eliminated. Dr. Sibson found, as will be seen by reference to his Medical Anatomy, that there is a point on the anterior aspect of the heart towards which all other parts converge, and which is itself almost motionless. In all delicate observations, it was here that the stethoscope, which was flexible and had a small cup, was applied. There was no friction to hear. The statement which he quotes from Dr. Halford, "that neither first nor second sound was heard", is beside the question. Dr. Leared must have heard sound under these conditions, as I have, or his assertion about it was simply unmeaning. $\mathrm{Had}$ he come to the same conclusion as Dr. Halford, I should probably never have written my remarks at all. The second sound disappears aitogether, and the first becomes exceedingly feeble; but any sound that is audible must be entirely independent of friction.

As regards the anæmic aortic or pulmonic murmur, Dr. Leared accepts my correction, but endeavours to attenuate its effect. When he has restated the proposition put by him as a crux, which I challenged, with the modifications required by his admission that the murmur accompanies instead of replacing the sound, I will again consider it. In the meantime, I may give my own version of the question as it now stands. The argument, as I understood it, was, that the shock-sound being replaced by a murmur in consequence of the altered condition of the blood, the shock and murmur owned the same causecollision or vibration of the blood. To this, my objection, admitted by Dr. Leared to be well founded, was fatal. The new ground now taken up is that, while it is impossible to deny that the sound and murmur coexist, this is only occasional, and the sound is feeble and degenerated i. e., apparently the sonorous vibrations are divided into shock and murmur. If, therefore, the shock-sound be not notably impaired when a murmur is present, the theory of the common origin of the first sound and murmur falls to the ground. We are now again in the field of observation. Unfortunately, the issue is not so simple and definite as when the coexistence of a sound and murmur only was in question. If it were, I should confidently expect an early surrender on this point also; for, according to my experience, not only does a first sound accompany an anæmic murmur, but this first sound is not otherwise diminished in intensity than through weak action of the heart. When, indeed, the heart's action is excited, the first sound is very loud, but sharp. The first sound must, of course, be sought where we hear it under other circumstances-at the apex or over the right ventricle, according as the murmur is aortic or pulmonary; and not for this occasion only over the aorta.

Dr. Leared's answers to my questions are before the reader, and there I am content to leave them, with one or two general observations. First, as to "the difficult question of the propagation and conduction of the sounds", on which a part of these answers turns : I see no end to the discussion if we must cease to accept the recognised methods of localising the source of a sound whenever this is required by the exigencies of Dr. Leared's theory. Errors arising from the conduction of sound do not prevent us from forming a confident diagnosis in disease, and ought not to be invoked to break the force of an adverse observation. Another part of these answers turns on the difficulties attending the production of shock-sounds in fluids. This is exactly the reason why we, the "unbelievers", are not even "convinced against our will", and refuse to reject, in favour of so uncertain a cause, the sudden tension of membrane and muscle which must occur and which cannot but be attended with sound. If we deny to the valves any share in the production of the sounds, we must positively explain their silence. I tried in vain to obtain Dr. Leared's attention to this. Dr. Leared kindly informs me that, when I whistle, it is the air issuing from my lips which forms the sound. Quite so. But he wants me to believe also that the boom of the drum is formed in the same way. There is just the same difference between the murmurs and the sounds of the heart as between the "toot" of the fife and the "beat" of the drum.

I ought to conclude here, but my attention is specially called to the fact that there are instances in which the first sound is louder over the base than over the apex. Well, these exceptional cases would be an interesting clinical study; but they do not invalidate the rule, with w hich this discussion alone is concerned.

An explanation, again, is put in my mouth of the second sound sometimes heard (in the neck), together with an aortic regurgitant murmur, which I repudiate. I do not attribute this second sound, or any second sound, to vibration of the valves only. I am in this a disciple of Dr. Markham, who showed that the elasticity of the valves, arterial and auriculo-ventricular, alike brings them into position to close the orifices before the pressure of the blood comes into operation; and of Dr. Sibson, who taught and proved that the second sound is produced by the sudden tension of the great vessel and valve together.

I feel that I owe an apology to Dr. Williams for intruding myself into this discussion. I did not consider that the great and imperishable monument of his work was shaken, or that it needed any support from me; but statements were confidently made which I could not but challenge, and I trust Dr. Williams will accept my apology, and with it my tribute of respect and admiration.

\section{ANIMAL VACCINATION.}

\section{By JOHN GREENE, L.R.C.P., Birmingham.}

At the present time, when the paucity of vaccine lymph is drawing public attention towards the question of supply, and when an impression is gaining ground that all available means are not employed by Government to that end, the right of anyone having a special and large experience of animal vaccination to express his views on that process will be granted.

I will premise that, in pressing forward, I am impelled by no mere love of change, but by a conviction that certain facts connected with vaccination have not as yet received a due recognition by those in authority, or, at any rate, if received, have not had a proper sequence of action. Further, I am not an advocate for the substitution of ordinary arm-to-arm vaccination by that direct from the calf; I desire merely to secure the advantages which that system affords as a means for the cultivation and renewal of the virus, and as a reserve source of supply in time of temporary pressure, the former being the chief aim ; that a certain percentage of the population may, either by preference or direction, be inoculated from animal-vaccine, would be simply a necessary incident. In my pamphlet, Good Vaccine Lymph, I871, I endeavoured to prove the necessity of an occasional renewal of the virus from a primary source, taking as my text an unknown or forgotten paper of Jenner, "Instructions for Vaccine Inoculation", found amongst the medical papers of my grandfather. The opinion expressed in this pamphlet received the cordial adhesion of many leading members of the profession, particularly of Mr. Robert Ceely, the well known author of those remarkable papers on the "Variolæ Vaccinæ", than which, as evidence of close and accurate scientific observation, it is impossible to conceive anything more complete.

In 1853 , the responsibility of keeping the virus up to a high state of efficiency hitherto resting with the profession, which by individual enthusiasm had nobly justified public reliance, was transferred ipso facto by Lord Lyttelton's Act to the legislature. That verve which responsibility gave to individual effort was extinguished, interest in the question for the time being paled before the universality of the practice and the supposed infallibility of the genius of public law.

This important duty so transferred has, since this Act, been fulfilled on the narrow basis of departmental opinion existing at that time and since. The radical defect of the law is, that, while stringently forcing upon the nation a certain saving virus, it has not taken a sufficiently broad view of the possible necessities of its nature and origin; as the use of this virus is compulsive, it is essential that the ruling idea concerning its source should be perfect at all points and satisfactorily ample in its dimensions, not only for the sake of disarming possibly ignorant suspicions, but for the conservation of its high prophylactic power.

It was, of course, much the pleasanter and smoother road for the learned framers of the Act to adopt the theory of unchangeability in the lymph under official supervision, rather than the weary and difficult path of those who from time to time sought to produce a new stock of high standard in relation to variola. It is not the first time that difficulty has been hidden under the cloak of dogma, and all in good faith has this been done ; for the evidence in favour of non-degeneration is certainly strong, till contrasted with the opposing facts and arguments which have accumulated and grown stronger since the time in question.

In all observations on the course of the vaccine in the human subject, it has not been sufficiently stated whether the presence of the typical vesicle in the vaccinations of a given stock has been meant to express that such was the average condition, the numerical majority. An experienced vaccinator is well aware that a number of children may be vaccinated from a weak or doubtful stock, and yet that certain of them will unfailingly exhibit a good vesicle, and vice versa. The superiority of "the most active kind of virus" (Jenner) over a poor virus is simply that it raises the average number of vesicles of the actual or ap- 
proximate Jennerian type, or vesicles in conformity on all points with Jenner's description.

We might ask those who assert the unchangeability of lymph to carefully compare any old stock, Jennerian or otherwise, that has been in use for many years, with a stock of lymph of an active kind whose date of origin from cow-pox is only three or four years previous, and which at the same time has been subject to equally good conditions of preservation as the old one ; or to compare the product of the old lymph with the exact description by Jenner in his "Instructions for Vaccine Inoculation"; they will find, as indeed is acknowledged by both sides in the controversy, though attempted to be explained away by the semper eadem phalanx, that there are marked differences, particularly with respect to the comparative frequency of certain transient epidermic occurrences or sequelæ. Whether these differences are important, is a matter upon which the right of freedom of opinion should be conceded and opportunity afforded by the State for that freedom to exercise itself in action. Let us remember, before we dogmatise, how little is known of the true life-history of any of these contagious disorders, or what is the influence that at certain times raises or lowers their virulence. The subject is full of anomalies and unanswered riddles, and so is the practice of vaccination, both animal and human.

If a public vaccinator observe a falling off in the power of his lymph, in a plain uncompromising manner he first seeks the cause, probably fails, and then proceeds to his remedy. If he have a very large clientzle, he may attempt to bring it up again by patient selection ; if he fail in this, or his clientèle be not really large enough for such a trial, he resorts, say, to the National Vaccine Institution, and receives by post lymph taken at hazard from the bulk of that in store, which has been supplied and paid for from numerous vaccination stations in correspondence with the institution; the only guarantees of value being, first, that afforded by the naked eye or a pocket-lens as to whether segregation has taken place, or epithelial or other deposit impairing its brightness; and, secondly, the periodical visit of the inspector.

It is probable that the critical duties of these gentlemen are not severely taxed. Owing to the care taken in the choice of public vaccinators, any fault existing cannot fairly be laid upon these gentlemen, but upon the system, a system which, I advance, is certainly calculated to produce a tolerable uniformity in the vaccination throughout the country, but an uniformity of a lower standard than ought to emanate through the Post Office from the central fountain of renewals. Is it proposed to continue this system as the ne plus ultra?

It has been here assumed that the public vaccinator has had recourse to the "National Vaccine Institution". But suppose, from his great care and other favourable conditions, that his type of vaccination is remarkably permanent, it is yet possible to conceive that those actual differences between old and new lymph, often described and discussed, and which frequently make themselves suddenly apparent, may also be created so gradually as to escape observation for years. There would always be a few children exhibiting an approximately typical vesicle resulting from the compromise between receptivity and inoculability, neither of which attributes has a fixed but a fluctuating value; the movement depending not only upon the vaccinator, as the selector of propagating specimens, but, perhaps upon some additional unknown influence.

Even on such a ground as this, it is unfair and impolitic to afford no opportunity for the use of recent lymph to such persons as desire it. Jenner himself noticed no change in his lymph after twenty years, but his judgment did not dogmatise ; he said in reference to this question, "Time alone will show". Now that time has come; we are in the midst of a sharp epidemic of variola, occurring in a population living for many years past under a coercive vaccination act. The dimen. sions of the epidemic of the last four years cannot surely be explained away by the mere increase of the population ; it would be almost a pity if figures could prove this, lest it should help to make us satisfied with a bad state of things.

During the first half of this century was observed a continually increasing popularity of vaccination and diminishing of small-pox, are we not now threatened with a reverse movement; increasing small-pox and diminishing prestige of vaccination? In the defect of the vaccine administration lies the strength of the anti-vaccinators. It is not wise to exercise activity in the direction of prosecution only, but in satisfying the public on the question of the origin of lymph. Jenner himself states that an imperfect variolous inoculation will not protect from variola; much less likely, then, is an imperfect vaccinal inoculation to do so.

It should be remembered, that in robbing small-pox of its contagious power by our artful scheme of passing it through the body of a cow, we do rob it of half its nature, its most virulent half, and retain only its milder power of infection. How then are we, with this dwarfed and semi-hybrid product, to fight against contagious small-pox, unless we take along with us the constant effort to approximate it, as nearly as may be consistent with safety, to its original character? And if we find that certain virulent yet safe qualities (the absence or presence of which must be judged of by average) are in effect absent, we must immediately seek a method to recover them.

Let us try to lower the present small-pox death-rate by raising the standard of the virus, accentuating its constitutional impression and encouraging revaccination by bending slightly to prejudice, whether well founded or not, when that bending will not entail any loss of value. It is here suggested that the authorities having charge in this country of the administration of the vaccination laws, shall add to their resources by instituting the practice of animal vaccination as a supplementary method in aid, but in no sense to supersede, the present arrangements.

By limiting the production of animal lymph to one central establishment, they will at once proclaim the undesirability of adopting it as a means of general vaccination, and by a concentration of attention render of certain issue such public benefit as the system has been proved to possess by the extensive experience of many places on the continent, and, to a slight extent, by private effort at home. The one thing essential is, that such an establishment should be carefully sheltered from the pernicious effect of a popular rush ; in other words, that the distribution of such lymph should be regulated not by the demand but by the easy capability of the resources of the day, jealously bearing in mind that the chief raison d'être would be the supply of an unimpeachable lymph for the purposes of renewal. That many persons would by preference be vaccinated in this way there is no doubt; but proper restrictions would be sufficient check to prevent any excess in number without impairing the liberty of those whose minds were set upon it, and who entertained a conscientious objection to hominal lymph.

The above considerations need not prevent the employment of animal vaccination for the production of virus for revaccination in time of epidemic variola ; but this would require even more stringently an unflinching application of the rules in detail as the danger of drawing non-effective lymph from pocks that would not mature would be increased by the pressure of demand. The experience at Brussels is here most valuable, and shows a success in revaccination by different Belgian physicians using dry points of 63 per cent. My own success in revaccination in Birmingham in $1870-7 \mathrm{I}$ direct from the animal, and counting in the few mere vaccinal successes, goes still higher, reaching 75 per cent.

The laissez faire system, so natural to the English character and so often wise, is, with regard to animal vaccination, a most unfortunate one. At this critical time for Jenner's great discovery, no looseness of practice should exist. The directing influence of authority over every single case of vaccination should be felt more and more ; but, if things are left alone, numerous establishments for animal vaccination will arise entirely without control, and in the hands of gentlemen who, striving to do good, yet may possibly lack experience, material resource, and even sometimes the necessary firmness in selection. The last state of things might be worse than the first. I appeal, through these columns, to the medical advisers of Her Majesty's Government to inquire again into the matter ; and to see if $\mathrm{I}$ am not right in thinking that, if animal vaccination must be practised, it should be under Privy Council regulation, which no one would more welcome than those gentlemen whose convictions have led them in this direction.

I desire now to mention a few of the opinions formed upon the subject after eight years' experience, during which time from four hundred to five hundred animals have been inoculated by me, either for vaccination or the purposes of experiment; some of these thoughts I have lately expressed in "Practical Notes onVaccination" (Birmingham $M e$ dical Review for October last). At present, it will be useful to briefly reiterate several points. During the above eight years, I have never seen any serious effect follow from the lymph being too severe in its operation, as has been asserted; in two cases at the most (revaccination) have I seen a rather deep excavation ensue, accountable for by the state of the patient's health at the time; in neither of these cases was the healing a protracted affair. In the first and second removes, the local effect is increased in intensity, requiring a somewhat more guarded insertion ; but with that limitation, no dread of its action need be entertained; it speedily loses this acrimony, and succeeds on the human subject pretty much as the cow-pox lymph itself, with a very slight average acceleration. The excellence and high standard of cowpox preserved and cultivated on the bodies of calves, equally with human lymph, is liable to lose in time a portion of its activity.

The lymph at present in use at Brussels is a very excellent lymph, but scarcely so active as the lymph of the Esneaux source employed some years ago, or quite so tenacious of its vitality. I know of no 
lymph better than the Brussels stock, yet it must yield. in several ways to that formerly in use.

It is unfortunate that the various Governments abroad, which carry on animal vaccination, have not accepted the most important fact concerning the origin of the vaccine disease that has been enunciated since Dr. Jenner's time ; and it is singular that it was the incongruity of his opinions thereon which, a score of years after his death, actually gave the impetus to the discovery of the truth by Mr. Robert Ceely. Strange, too, is it that Jenner should have failed to grasp that other integral portion of a dual fact that, not only would vaccination protect from variola, but that small-pox of cows was the small-pox of humanity in the cows. There is traditional evidence to prove that this latter knowledge was equally the property of the vulgar, as was the first proposition from which Jenner acknowledges he derived his earliest inspiration. Small-pox was occasionally inoculated upon the cow previously to its use on the human subject, in order " to make it mild".

The first Vaccination Act was cotemporary with Mr. Ceely's observations on this head, and before the world had been enlightened by them as to what the vaccine disease really was. Lord Ellenborough, by expressly forbidding small-pox inoculation, almost seems to have been a party to the continuance, up to the present date, of the false notion that vaccinia was something essentially different from variola, whilst clearly enough protecting from it.

It is wonderful that such a fact should not have carried with it a conviction of its identity of origin. Had Mr. Ceely's observations been made a few years earlier, or had Jenner, in the young bud of his enthusiasm, as clearly elucidated the origin of vaccinia as he did its effects, there is little doubt that the Act of 1840 , when forbidding small-pox inoculation, would have added the words "without first transmitting the virus through the cow".

The animal vaccinators of the Continent, were they yet fully aware of the relation of small-pox and cow-pox, would not wait for years till some case of accidental contagion turned up, enabling them to make a fresh start, with trumpet-sound, from a " spontaneous case". I sincerely hope that, if ever the Government here should decide to cultivate vaccine lymph or calves, as a supplement to the present method, that they will entertain no illusions of this kind, but produce the article they require by exposing animals, from time to time, either to infection or direct inoculation as may be best, thus reproducing the conditions existing when this hybrid disease was comparatively common.

At present, there is no desire apparent at head-quarters to renew the lymph. In September last, supposed cow-pox broke out in a farm near Canterbury. The authorities were informed of this, but declined to take any steps, saying that they did not use cow-pox lymph however, in this case, they were fortunate in their immobility. I performed a kind of modern Canterbury pilgrimage, including a mortification, upon finding the complaint to be that dreadfully monotonous "white vesicle". One of the causes of the well-known differences in power of primary stocks may possibly be due to whether the animal has been affected by contagion or by inoculation. The task, however, of producing vaccinia from variola is not an easy one, yet further experience would make it less difficult; it has been done in England many times by Ceely and Badcock, and once by myself. (See "Practical Notes on Vaccination", Birmingham Medical Revierv, Oct. 1876.)

\section{THERAPEUTIC MEMORANDA,}

\section{ON THE INFLUENCE OF SALICYLIC ACID IN} TYPHOID FEVER.

THE following case is an instance of the remarkable fall of temperature caused by the use of salicylic acid. The patient, a boy aged 14, had typhoid fever. He was given salicylic acid in ten-grain doses every four hours. On the twelfth day of the fever, I found that his temperature had risen to $103 \frac{4}{5}$ deg. Fahr., and his pulse to II6 ; moreover, he was somewhat comatose, his tongue very dry and furred, in consequence of his parents having left off the medicine as he had had four liquid stools. I immediately increased the dose to twelve grains every three hours, and his brandy to three ounces daily. On the following evening (i.e., twenty-four hours after), his temperature had fallen to ror deg. Fahr. and his pulse to 104 ; tongue moist and cleaner. He also readily answered any questions put to him. The medicine was then given every four hours, and the boy is now convalescent. In this case, a fall of nearly three degrees took place on the resumption of the acid.

In another case that presented all the symptoms of a severe attack of typhoid, this drug apparently cut it short.

$$
\text { E. A. SNell, City Road. }
$$

TREATMENT OF RINGWORM BY GOA POWDER.

IN several articles recently published in the BRITISH MEDICAI JOURNAL, the virtues of this remedy have been discussed. Having formerly been a resident in the East for nearly two years, and having treated a large number of cases of the so-called "Doby's ringworm", or tinea circinatus, both among natives and Europeans, I may add my mite to the inquiry. This disease, which is so common in India and China that almost every individual becomes at some period affected with it, is successfully treated with several external applications, such as tincture of iodine, solutions of mercury, etc. Undoubtedly, the most certain and rapid is that of Goa powder. I have found, in acute cases, that one application was usually followed by recovery. In chronic cases, two or three may have been necessary to thoroughly eradicate the disease. In no single instance do I remember the employment of this drug to have failed in effecting the object desired.

A. Hughes Bennetr, M.D., M.R.C.P., Medical Registrar, Westminster Hospital.

\section{TREATMENT OF RINGWORM BY THE TINCTURE OF PERCHLORIDE OF IRON.}

Amongst the many remedies that have been recommended for this common and sometimes intractable disease, I have observed lately notices of the Goa powder, cassia lata, and chrysophanic acid, but have failed to observe any reference to the treatment of the disease by the use of the tincture of perchloride of iron. I have tried it on several occasions with most satisfactory results ; sometimes, one application being sufficient to effect a complete cure. It is a clean and simple remedy, well worthy of attention. I have known cases do well under the application of common ink ; this, I presume, must be owing to the iron it contains.

James Dobbie, M.D., F.F.P.S.Glas., Hillhead.

THE RESPIRATOR-INHALER.

A VERY useful respirator-inhaler was shown in London more than twelve months ago by Mr. Carrick of Glasgow. It consists of a hollow breast-plate divided into two compartments. The larger of these contains a piece of felt; the smaller one can receive, when desired, a piece of sponge to be impregnated with medicinal solution. There is, moreover, a piece of India-rubber tubing and a mouth-piece. The breast-plate is about five inches long by three inches and a half broad and half an inch thick, and is worn inside the coat. Thus the heat of the body volatilises the inhalant, and the patient can sit, stand, or walk about while occupied in inhalation. The layer of felt in the respirator acts as an efficient filter of the inhaled air, so that Mr. Carrick, while wearing his respirator, was able to remain some time in a cloud of smoke produced by the combustion of damp straw, the smoke from which is especially distressing and suffocative. I am induced to send these few remarks from seeing the notice in the JourNal of Dr. William Roberts's respirator-inhaler. Carrick's respirator and also his very complete inhaler are sold by Messrs. Beaumont and Co., I, Cecil Street, Strand.

John C. Thorowgood, M.D., F.R.C.P., Welbeck Street.

\section{OBSTETRIC MEMORANDA.}

\section{OCCURRENCE OF CONFLUENT SMALL-POX AT THE SEVENTH MONTH OF PREGNANCY.}

I was called to Mrs. $\mathrm{H}$. on June 7 th, $\mathrm{r} 874$, the messenger stating her to be in labour. Upon arrival, I found her very feverish, vomiting, with intense pain in the back. Upon examination, the os uteri was found quite closed and rigid, the vagina dry and hot. As small-pox was then prevalent in the town, I felt sure she was beginning to have it, and prescribed accordingly. The next day, the whole body was covered with the confluent eruption, and the case went through a most severe course. The treatment pursued was exclusion of light, with nitric acid and liq. arsenicalis internally. She made a good recovery, with but slight pitting. She went to the full term, when she was delivered by my assistant of a female child, strong and healthy in every way, and quite free from any indication of the mother's illness. When the child was two months old, I vaccinated it, in the first place with points, without effect; I then tried capillary tubes, with the same result. After that, I vaccinated from arm to arm, without any effect or slightest redness produced. I think the insusceptibility to vaccination may clearly be traced to the fact of the child having had small-pox in the uterus.

Henry Robinson, L.R.C.P.Ed., Chesterfield. 